\title{
MECHANICAL PROPERTIES OF COMPOSITES WITH TITANIUM DIBORIDE FABRICATED BY SPARK PLASMA SINTERING
}

\begin{abstract}
Microstructure and mechanical properties of the $316 \mathrm{~L}$ steel composite reinforced with $\mathrm{TiB}_{2}$ phase were examined. The test materials were obtained by SPS technique from powders. From testing of the mechanical properties it follows that the optimum temperature for the fabrication of $316 \mathrm{Lsteel}-\mathrm{TiB}_{2}$ composites by SPS is $1100^{\circ} \mathrm{C}$. Studies have also proved that the critical content of $\mathrm{TiB}_{2}$ phase in steel matrix should not exceed $6 \mathrm{vol} \%$. Above this level, the plastic properties of the composite become unstable and strongly dependent on the time of sintering.
\end{abstract}

Keywords: Composite, Spark Plasma Sintering (SPS), Mechanical properties

\section{Introduction}

By the technology of powder metallurgy, materials difficult to obtain by other methods are produced. The development of SPS and HP-HT methods has significantly expanded the possibilities for controlled synthesis of new materials. The high sintering pressure applied in powder metallurgy is an effective tool for the control of diffusion process. New opportunities emerge along with the introduction of SPS technology based on high-current heating process. The specific character of current heating allows for the accumulation of energy and intense heating of contact points between the powder particles touching each other. The result is rapid formation of intergranular bridges, which serve as a path for the spreading diffusion process. The additional effect of compaction pressure is densification of processed material and increased area of intergranular bonds [1-5].

An important feature of the SPS method is that it allows preserving the original grain size of powder components and avoids the excessive grain growth. Materials obtained by the SPS technique are characterized by high structural homogeneity produced within the entire volume of a sample. The method also offers high speed, precise selection of the sintering parameters and energy efficiency. The disadvantages include the need to work with high direct current and relatively small size of the resulting end product [6-8]. In recent years, the SPS method has been widely used in the manufacture of composite materials based on copper [9,10], nickel [11,12], and aluminium [13-15], or iron [16-18]. Studies have mostly focused on optimization of the sintering process and achieving satisfactory physical, mechani- cal, electrical and tribological properties. However, accurate determination of mechanical properties of the sintered composite materials based on ferro-alloys, particularly the determination of the yield strength and tensile strength $\mathrm{R}_{\mathrm{m}}$, has some limitations, which are mostly due to the dimensions of sinters obtained by the method of SPS. The composite sinters discussed in this study, processed by SPS, had a diameter of $20 \mathrm{~mm}$ and thickness comprised in the range of 7-8 $\mathrm{mm}$. In view of the dimensions so small, it was necessary to develop own genuine methods for testing of the mechanical properties. It was decided to implement the tensile test, as characterized by high repeatability of results and accuracy in the determination of different mechanical parameters. The developed method enabled the tensile test to be carried out at elevated temperatures of up to $1000^{\circ} \mathrm{C}$. The option of cutting out eight tensile specimens from one sinter has created the possibility of working on samples manufactured under the same conditions, and therefore giving the same reproducibility of results for each type of the sintered material tested. For example, Liu et al. [19] conducted tensile tests at room temperature on the superaustenitic stainless steelreinforced with 10-30vol\% TiN. The composites were obtained by hot-isostatic pressing. Tensile tests were carried out on cylindrical specimens with threaded ends. Compared to the matrix without reinforcement, the composites were characterized by high yield strength (UTS), but low tensile strength and elongation. The best results in terms of UTS and elongation were obtained on composites containing $10 \mathrm{vol} \% \mathrm{TiN}$. Increasing the content of reinforcement to $30 \mathrm{vol} \%$ has resulted in a significant drop of both the tensile strength and elongation. 
The main aim of the studies described in this article was testing the mechanical properties of 316 Lsteel- $\mathrm{TiB}_{2}$ composites, especially their behaviour at elevated temperatures. The results are continuation of the research discussed in [16,20], where other methods of consolidation of powders based on Fe and $\mathrm{TiB}_{2}$ were described along with their impact on physical and mechanical properties of the sintered composite materials. The present research is focused on the composites containing $\mathrm{TiB}_{2}$ in an amount from 2 to $8 \mathrm{vol} \%$. This content of the reinforcement produces materials with a wide range of properties. The 316Lsteel- $\mathrm{TiB}_{2}$ composites are materials dedicated primarily for high temperature applications as a cheaper alternative to composites used currently [21-25]. Therefore, in the studies, particular emphasis was put on the determination of mechanical properties at elevated temperatures.

\section{Experimental procedure}

For the manufacture of composites by SPS, powders of AISI316L austenitic commercial steel $(25 \mu \mathrm{m}$ in diameter, KAMB Import-Export) and $\mathrm{TiB}_{2}$ (99.9 wt.\% purity, 2.5-3.5 $\mu \mathrm{m}$ in diameter, H.C. Starck) were used. Powder compositions were prepared by mixing appropriate components in TURBULA for 8 hours.

Four variants of composites reinforced with $2-8$ vol $\% \mathrm{TiB}_{2}$ were fabricated. The tested materials were sintered by SPS in an FCT HPD5 device (Germany). Pressing of powder mixtures took place in a graphite die at a maximum pressure of $35 \mathrm{MPa}$ in a vacuum environment. The compaction under a pressure so low does not affect the melting point of the material [26]. The vacuum and long-time of pressing were used to vent the mixture charged into the die. Then, a protective gas (argon) was introduced into the sintering chamber. Sintering was conducted at $1000^{\circ} \mathrm{C}$ and $1100^{\circ} \mathrm{C}$ The time of sintering was 5 and 30 minutes. The heating rate was $200^{\circ} \mathrm{C} / \mathrm{min}$. The sintered specimens were $7-8 \mathrm{~mm}$ high and had a $20 \mathrm{~mm}$ diameter.

Microstructure of the $316 \mathrm{Lsteel}-\mathrm{TiB}_{2}$ composite was examined by SEM using a high-resolution scanning electron microscope (Hitachi SU-70) equipped with a field emission gun and a set of Thermo detectors. Chemical analysis of the sintered materials was done by WDS.

Microhardness was tested under a load of 2.94 N with FM-7 Vickers hardness tester (Future-Tech Corp.). Ten microhardness measurements were taken on each sample, and then the average value was calculated. The standard deviation of HV0.3 was less than $4 \%$ of the average value. As a next step in the studies, from each sintered composite $(\mathrm{h}=7-8 \mathrm{~mm}, \phi=20 \mathrm{~mm})$, the tensile specimens were prepared by electrospark method. From each sinter, 7-8 specimens with dimensions of $0.5 \mathrm{~mm} \times 0.5 \mathrm{~mm}$ were cut out (Fig. 1a). One of the cut out specimens is shown as an example in Figure 1b. Testing of mechanical properties was carried out on specimens with a $5 \mathrm{~mm}$ base deformed at a rate of $6 \times 10^{-4} \mathrm{~s}^{-1}$. Tensile tests were performed at temperatures ranging from $20^{\circ} \mathrm{C}$ to $950^{\circ} \mathrm{C}$. Studies involved the use of a testing machine equipped with a furnace for high temperature testing (up to $1000^{\circ} \mathrm{C}$ ). A jaw of the design adapted to stretching of micro specimens cut out by the method described in literature [20] was used.

\section{Results and discussion}

Figure 2 compares the microstructure of a composite based on $316 \mathrm{~L}$ stainless steel with different content of $\mathrm{TiB}_{2}(2-8 \mathrm{vol} \%)$. A uniform distribution of the reinforcing phase in a steel matrix is visible accompanied by the presence of small precipitates distributed at the $\mathrm{TiB}_{2}$ phase boundary and in the matrix (Figs. 2,3). The size of the precipitates ranges from a few up to several microns. Chemical analysis (WDS) of these small precipitates has indicated the presence of boron and chromium. They were formed during the sintering process by SPS. In the same composite but sintered under high pressure, phases containing chromium and boron were not observed to occur [26,27].

Figure 4 shows the results of microhardness measurements. Based on these results it was concluded that microhardness depends on the content of reinforcing phase in the composite matrix and on the sintering conditions (time and temperature). a)

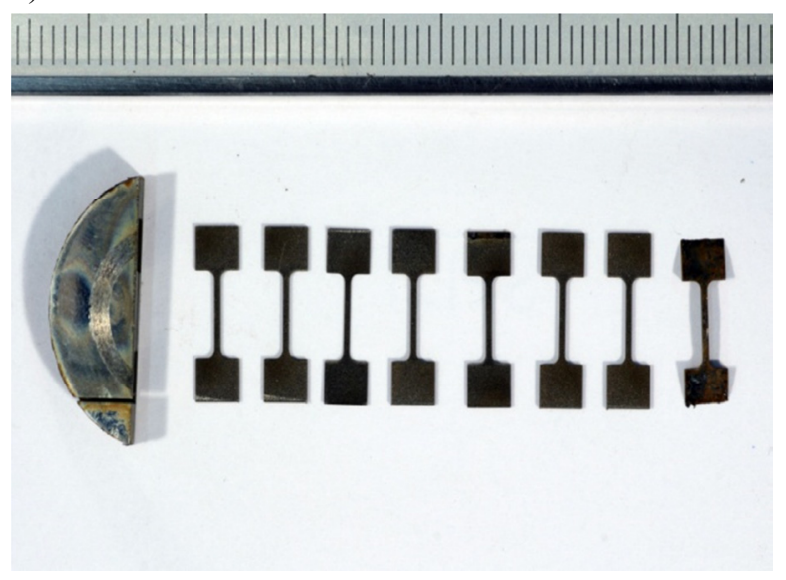

b)

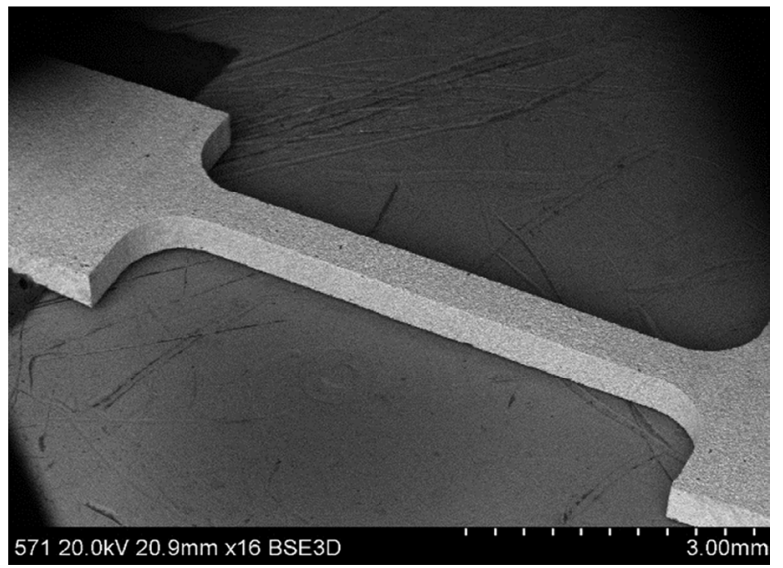

Fig. 1. a) A set of specimens, and b) example of a tensile specimen cut out by the electrospark process ( $316 \mathrm{~L}$ steel- 8 vol $\% \mathrm{TiB}_{2}$ composite) 
a)

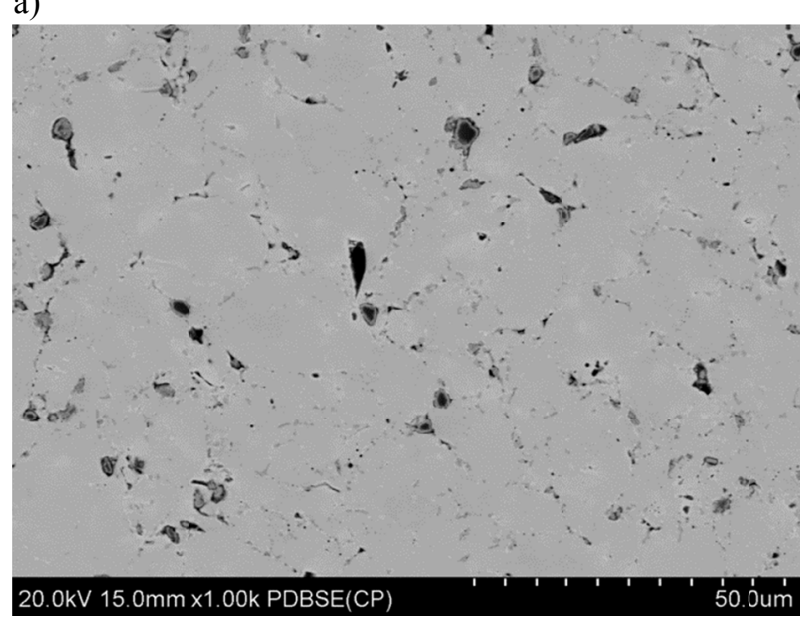

c)

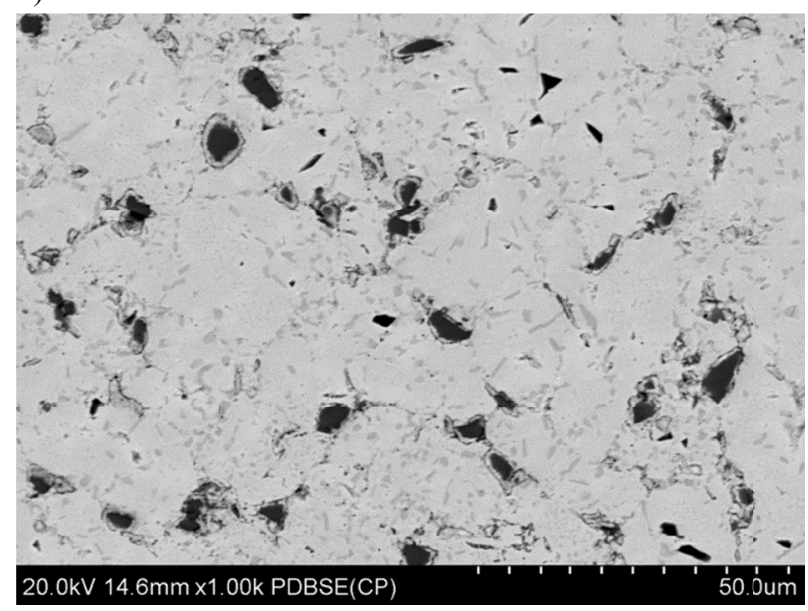

b)

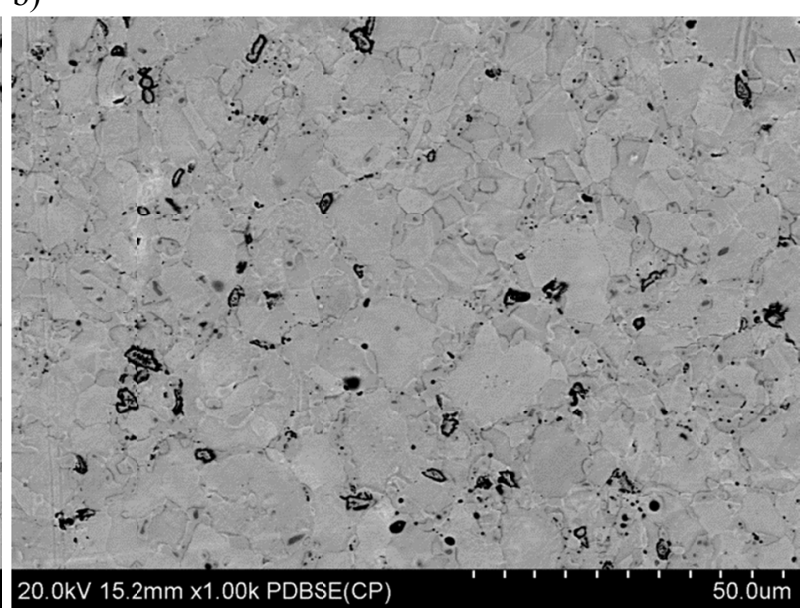

d)

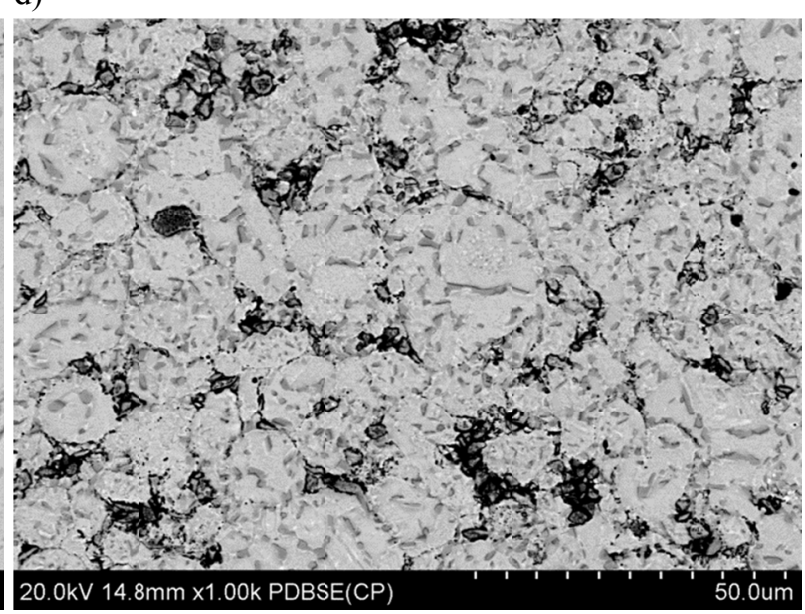

Fig. 2. Microstructure (SEM) of composites sintered at $1100^{\circ} \mathrm{C}$ for 5 minutes: a) $2 \mathrm{vol} \% \mathrm{TiB}_{2}$, b) $4 \mathrm{vol} \% \mathrm{TiB}_{2}$, c) $6 \mathrm{vol} \% \mathrm{TiB}_{2}$ and d) $8 \mathrm{vol} \% \mathrm{TiB}_{2}$
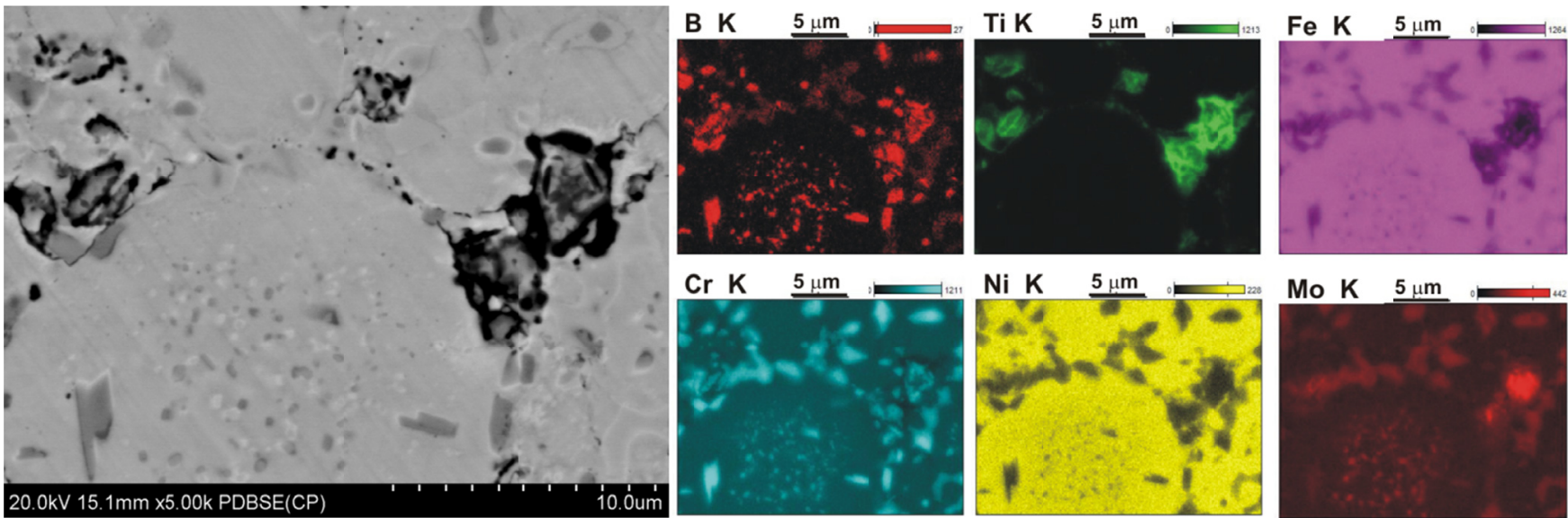

Fig. 3. Microstructure (SEM) and surface analysis (WDS) of the $316 \mathrm{~L}$ steel- $8 \mathrm{vol} \% \mathrm{TiB}_{2}$ composite (sintered at $1100^{\circ} \mathrm{C}$ for $5 \mathrm{minutes}$ )

Microhardness gradually increases with the $\mathrm{TiB}_{2}$ content increasing in the matrix. It is low in the range of 175-235 $\mathrm{HV} 0.3$ for the sintering temperature of $1000^{\circ} \mathrm{C}$ and the time of 5 and 30 minutes, but increasing the temperature by $100^{\circ} \mathrm{C}$ definitely improves the microhardness raising it by $60-80 \%$. Microhardness of the 316 Lsteel- $\mathrm{TiB}_{2}$ composite was in the range of 330-415 $\mathrm{HV} 0.3$ for the sintering temperature of $1100^{\circ} \mathrm{C}$ and time of 30 minutes.
Tensile tests were performed on specimens obtained in four time-and-temperature variants of the SPS process. Two sintering temperatures were applied, i.e. $1000^{\circ} \mathrm{C}$ and $1100^{\circ} \mathrm{C}$, and the sintering time of 5 and 30 minutes. Comparing the results of mechanical tests obtained for different variants of the sintering process (Figs. 5-8) has demonstrated that of critical importance for the specimens obtained within a given range of the SPS parameters is the sintering temperature. The temperature of the 
a)

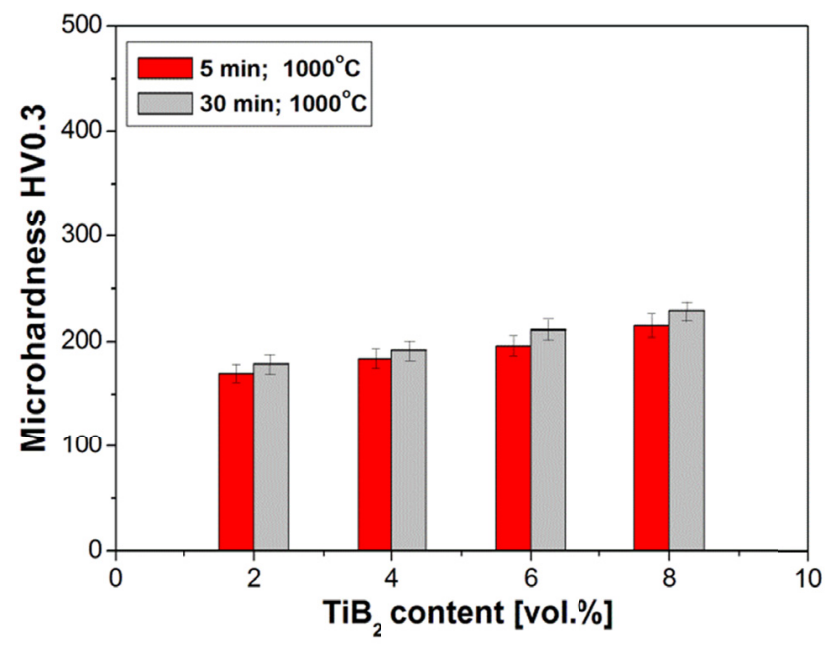

b)

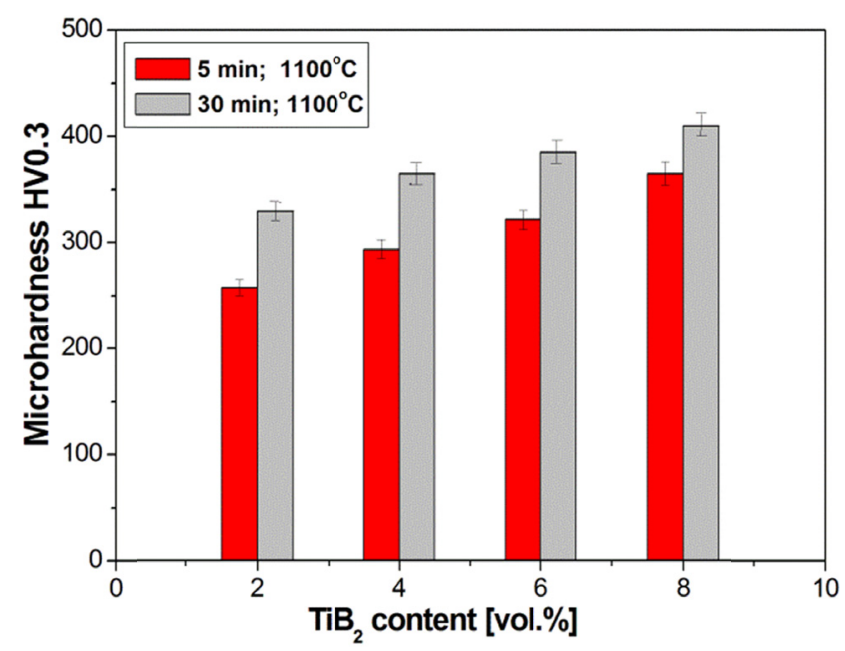

Fig. 4. Microhardness of the $316 \mathrm{~L}$ steel- $\mathrm{TiB}_{2}$ composite sintered by SPS at: (a) $1000^{\circ} \mathrm{C}$ and (b) $1100^{\circ} \mathrm{C}$

sintering process was selected basing on previous experience with sintering the $316 \mathrm{~L}$ austenitic stainless steel powder and on thermodynamic predictions regarding the diffusion process taking place in an $\mathrm{Fe}-\mathrm{TiB}_{2}$ system. The obtained results showed that the temperature of $1000^{\circ} \mathrm{C}$ can not provide the consolidation of composite components at a level of the intermolecular diffusion. The measured after-sintering density of the composite has reached the level of $82-85 \%$ of the theoretical density, while porosity was in the range of $6-18 \%$ [16]. This proves absence of the liquid or semi-liquid phase during the consolidation process, which should be reflected in the results of mechanical tests shown in Figures 5-8. The best mechanical properties at the sintering temperature of $1000^{\circ} \mathrm{C}$ were obtained for the variant with $6 \mathrm{vol} \%$ $\mathrm{TiB}_{2}$, where the following values of the mechanical properties a)

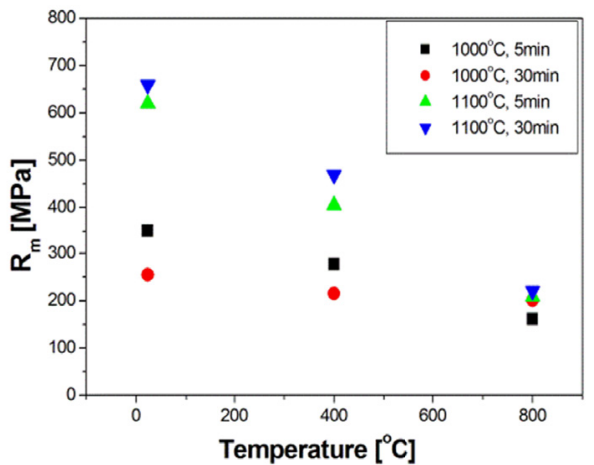

b)

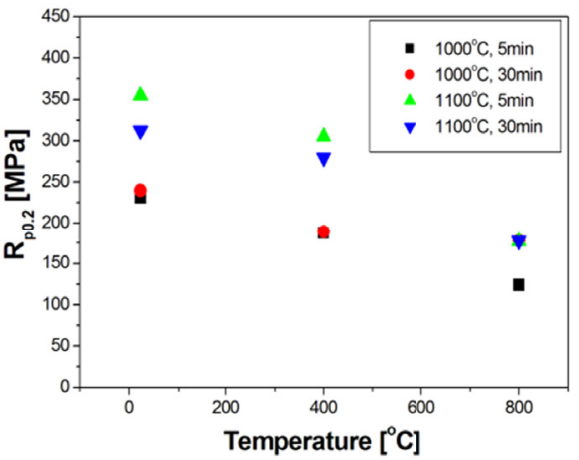

c)

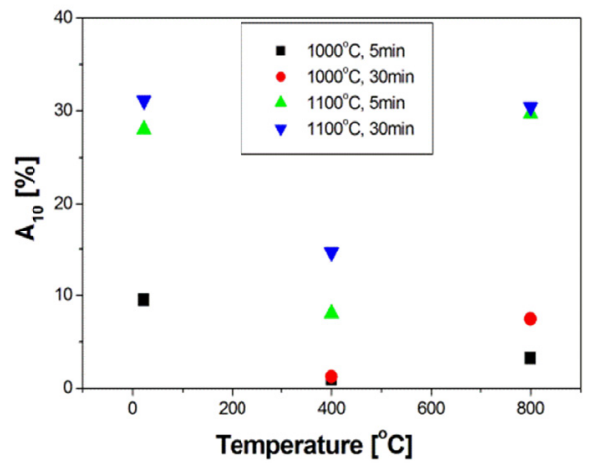

Fig. 5. The obtained mechanical properties: (a) tensile strength $\left(\mathrm{R}_{\mathrm{m}}\right)$, (b) yield strength $\left(\mathrm{R}_{\mathrm{p} 0.2}\right)$, (c) elongation $\left(\mathrm{A}_{10}\right)$ determined during the tensile test of $316 \mathrm{~L}$ steel- $2 \mathrm{vol} \% \mathrm{TiB}_{2}$ composite

a)

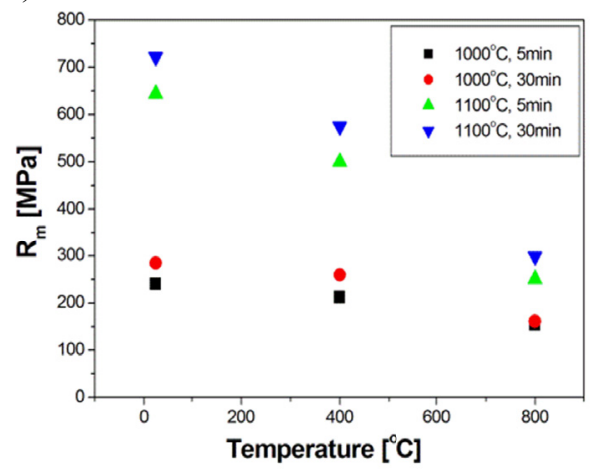

b)

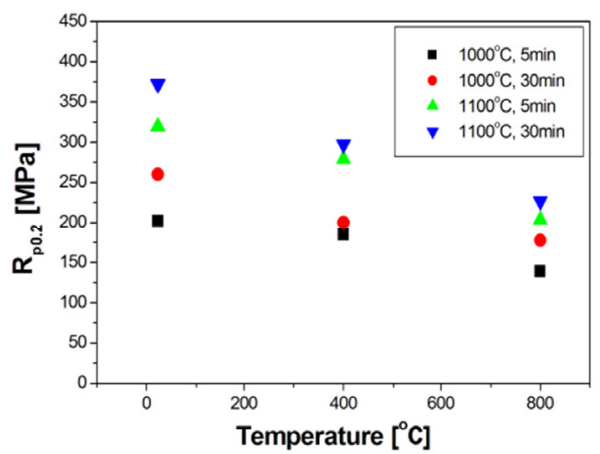

c)

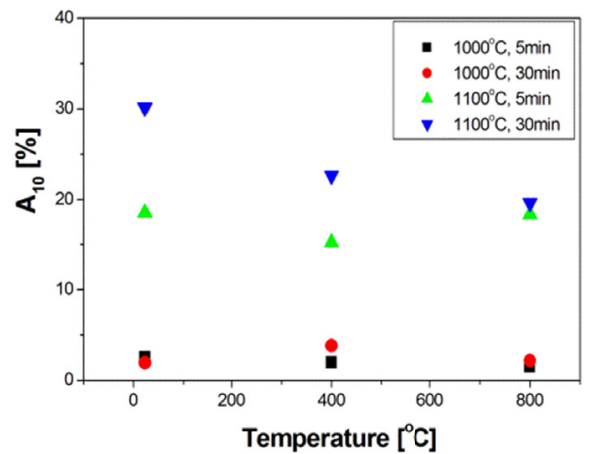

Fig. 6. The obtained mechanical properties: (a) tensile strength $\left(\mathrm{R}_{\mathrm{m}}\right)$, (b) yield strength $\left(\mathrm{R}_{\mathrm{p} 0.2}\right)$, (c) elongation $\left(\mathrm{A}_{10}\right)$ determined during the tensile test of $316 \mathrm{~L}$ steel- $4 \mathrm{vol} \% \mathrm{TiB}_{2}$ composite 
a)

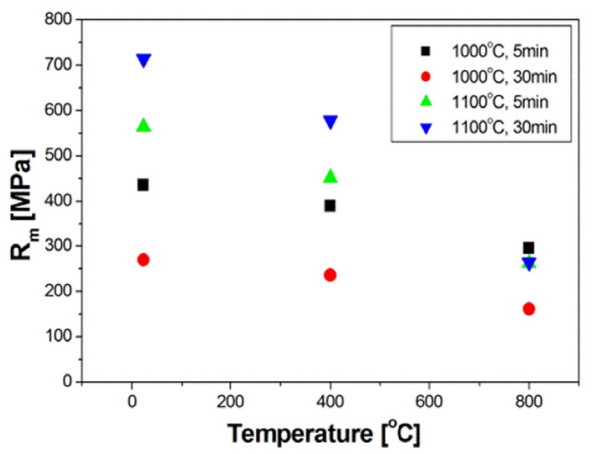

b)

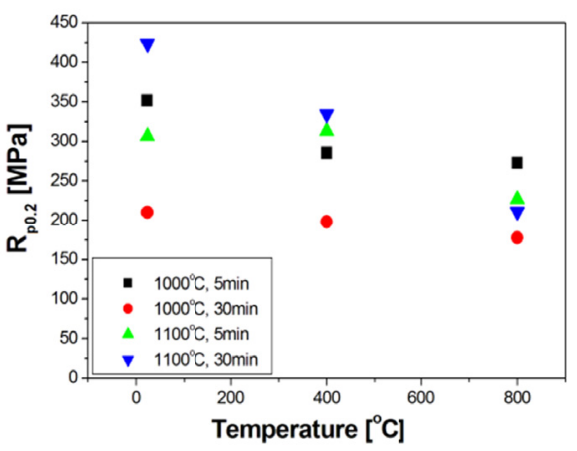

c)

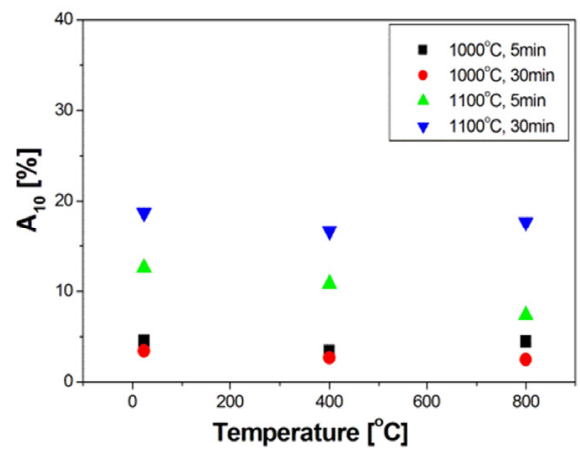

Fig. 7. The obtained mechanical properties: (a) tensile strength $\left(\mathrm{R}_{\mathrm{m}}\right)$, (b) yield strength $\left(\mathrm{R}_{\mathrm{p} 0.2}\right)$, (c) elongation $\left(\mathrm{A}_{10}\right)$ determined during the tensile test of $316 \mathrm{~L}$ steel- $6 \mathrm{vol} \% \mathrm{TiB}_{2}$ composite

a)

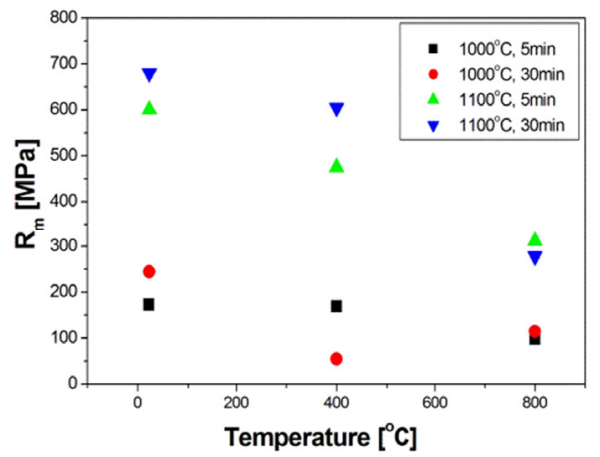

b)

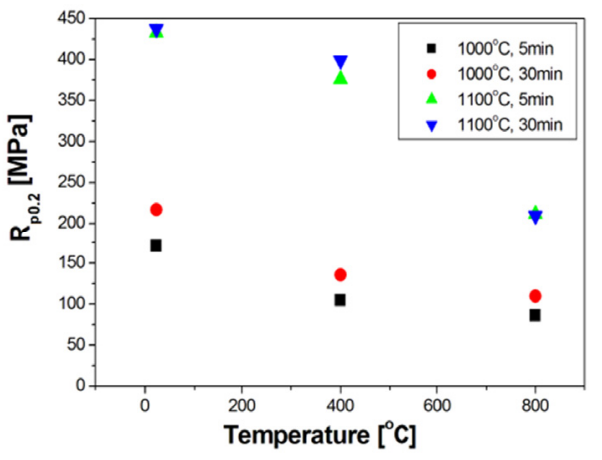

c)

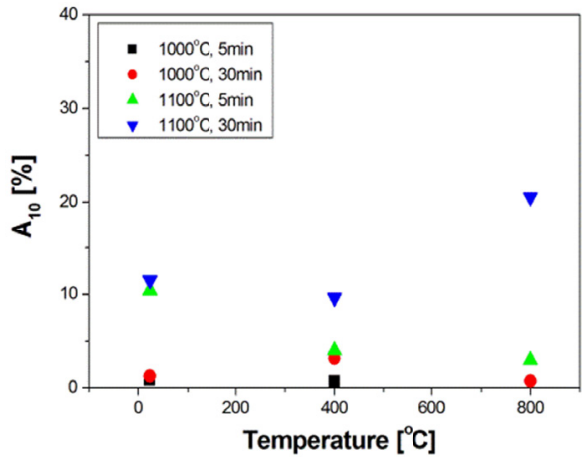

Fig. 8. The obtained mechanical properties: (a) tensile strength $\left(\mathrm{R}_{\mathrm{m}}\right)$, (b) yield strength $\left(\mathrm{R}_{\mathrm{p} 0.2}\right)$, (c) elongation $\left(\mathrm{A}_{10}\right)$ determined during the tensile test of $316 \mathrm{~L}$ steel- $8 \mathrm{vol} \% \mathrm{TiB}_{2}$ composite

were obtained for the $1000^{\circ} \mathrm{C}-5 \mathrm{~min}$ specimen: $\mathrm{R}_{\mathrm{m}}=450 \mathrm{MPa}$, $\mathrm{R}_{\mathrm{p} 0.2}=350 \mathrm{MPa}, \mathrm{A}_{10}=4 \%$. Analysis of the effect of sintering time ( 5 and 30 minutes) on the properties obtained in samples sintered at $1000^{\circ} \mathrm{C}$ gave inconclusive results. This may suggest balancing on the edge of conditions which provide the consolidation of powder at the diffusion border with the participation of semi-liquid phase. Increasing the sintering temperature to $1100^{\circ} \mathrm{C}$ produced material with much better mechanical properties. Figure 2 shows the microstructure of non-deformed samples containing different amounts of $\mathrm{TiB}_{2}$, i.e. from $2 \mathrm{vol} \%$ to $8 \mathrm{vol} \%$. The samples were obtained by sintering at $1100^{\circ} \mathrm{C}$ for 5 minutes. It was a variant of the sintering temperature which provided the best mechanical properties, i.e. strength and ductility, in all samples tested (Figs. 5a-8a). In all cases examined in this variant (the content of the reinforcing phase from $2 \mathrm{vol} \%$ to $8 \% \mathrm{TiB}_{2}$, the sintering temperature of $1100^{\circ} \mathrm{C}$ ), high values of the tensile strength $\mathrm{R}_{\mathrm{m}}$, i.e. exceeding $600 \mathrm{MPa}$, were obtained at room temperature. The yield strength $\mathrm{R}_{\mathrm{p} 0.2}$ showed similar favourable characteristics. Increasing the deformation temperature in a sequence of $20-400-800^{\circ} \mathrm{C}$ resulted in a decrease of mechanical properties following anon-linear course of changes (Figs. 5b-8b), where the rate of decrease was increasing with the increase of temperature.

In the case of elongation $\mathrm{A}_{10}$, a strong ductility-limiting factor was the content of the reinforcing $\mathrm{TiB}_{2}$ phase. Exceeding the $6 \mathrm{vol} \% \mathrm{TiB}_{2}$ content in steel matrix brought sharp decline of ductility (Figs. 5c-8c). This was particularly true in the case of samples sintered for 5 minutes. A characteristic feature of samples obtained by SPS at $1100^{\circ} \mathrm{C}$ was the occurrence of a minimum ductility at the temperature of $400^{\circ} \mathrm{C}$. This was particularly evident in the case of samples with the lowest and highest content of $\mathrm{TiB}_{2}$, i.e. $2 \mathrm{vol} \%$ and $8 \mathrm{vol} \%$, respectively.

Analysis of the results has indicated that mechanical properties of the resulting sintered composites are strongly influenced by the time of sintering. The optimum sintering temperature at a level of $1100^{\circ} \mathrm{C}$ enabled obtaining fast bond between the particles of powder and the degree of consolidation exceeding in all variants $97 \%$ [16]. This proves the appearance of a liquid phase and efficient diffusion-based exchange of components. Even the sintering time as short as 5 minutes was sufficient to produce the material with satisfactory mechanical properties. In all the cases examined, increasing the sintering time to 30 minutes has resulted in an improvement of the mechanical and plastic properties. A particularly advantageous increase of elongation was observed in the samples with $8 \mathrm{vol} \% \mathrm{TiB}_{2}$. These samples after a long time of sintering showed the increase of ductility proportional to the increase of deformation temperature (Fig. 8c $\mathrm{A}_{10}$ for steel-8vol\% $\% \mathrm{TiB}_{2}$ composite, $1100^{\circ} \mathrm{C}-30 \mathrm{~min}$ ). A similar, although less pronounced, relationship was observed in samples with the lower content of $\mathrm{TiB}_{2}$. In these samples, the sintering time of 5 minutes was sufficient to provide the required ductility. In contrast, samples sintered at $1100^{\circ} \mathrm{C}$ for 5 minutes and deformed at $800^{\circ} \mathrm{C}$ showed the ductility drop to $2 \mathrm{vol} \%$. The 
reason was the difference in the structure of phase boundaries caused by the sintering time. The shorter time of 5 minutes was sufficient to effect a reaction involving the liquid phase and to obtain a high level of consolidation of the individual particles with small thickness of the resulting boundary. As a consequence, the structure with locally varying chemical composition was formed, in which the deformable phase was mixed with the precipitates of hard phases. The longer time of sintering, i.e. 30 minutes, has brought structure homogenization advantageous for the plastic phases. Additionally, as observed in other studies [20], in the process of deformation at elevated temperature, the structure was consolidated and its ductility reduced due to the dynamic precipitation. Longer time of sintering produces (30 minutes) the structure more stable thermodynamically. Then the dynamic precipitation proceeds with less intensity than it does in the structure obtained as a result of the short time of sintering (5 minutes). Under such conditions, the main process accompanying the high temperature deformation is sliding along the grain boundaries not hindered by precipitation. The occurrence of this phenomenon is also encouraged by a large volume of material with the homogeneous structure and high ductility within the grain boundaries. This is visible in the composite microstructure examined on fractures of the specimens stretched at high temperatures (Figs. 9,10). A high level of homogeneity was observed on the entire cross-sectional area of sample with gently rounded structure components indicating the plastic flow of material.

\section{Conclusions}

Testing of mechanical properties has proved that the optimum temperature for the fabrication of $316 \mathrm{~L}$ steel- $\mathrm{TiB}_{2}$ composites by SPS is $1100^{\circ} \mathrm{C}$. The use of lower temperature can not produce stable and fast intermolecular bonds that benefit from the appearance of a liquid phase. Important is also the time of sintering, as it affects the degree of reaction between different components of the system, and thus the homogeneity of resulting microstructure. This is particularly well visible during deformation carried out at high temperature of $800^{\circ} \mathrm{C}$, when the mechanical properties of the examined material are affected by the additional processes, which do not occur at room temperature. These include, among others, the dynamic precipitation and sliding along grain boundaries. Detailed examinations of the properties of the obtained sinters show that the $\mathrm{TiB}_{2}$ phase content in a steel matrix should not exceed $6 \mathrm{vol} \%$. When this level is exceeded, the plastic properties become unstable and strongly dependent on the sintering time. The maximum tensile strength $\mathrm{R}_{\mathrm{m}}$ assumes its lowest values when the content of $\mathrm{TiB}_{2}$ in the composite is $2 \mathrm{vol} \%$, while in the range of $4-8 \mathrm{vol} \% \mathrm{TiB}_{2}$ a constant high level of $\mathrm{R}_{\mathrm{m}}$ is obtained. Considering the data obtained it can be concluded that the optimum content of $\mathrm{TiB}_{2}$ in the tested composites based on a $316 \mathrm{~L}$ steel matrix is $4 \mathrm{vol} \%$. This composite material obtained by SPS has the highest tensile strength and satisfactory yield strength and is suitable for use in a wide range of temperatures. a)

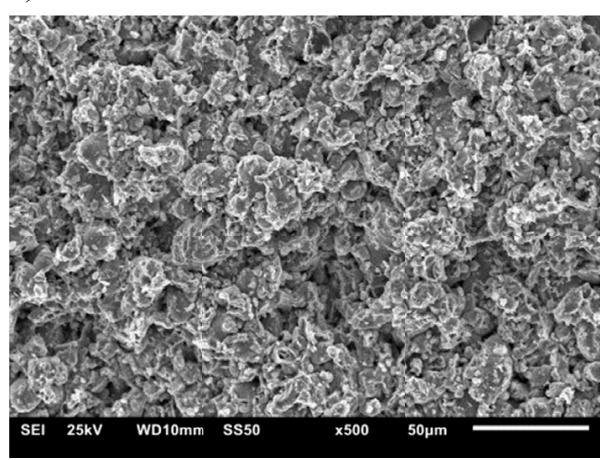

b)

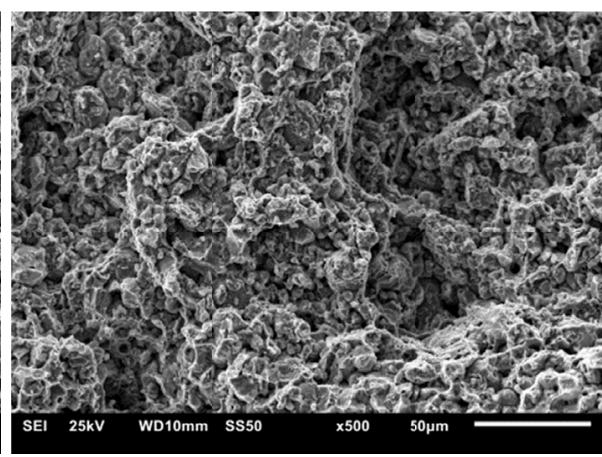

c)

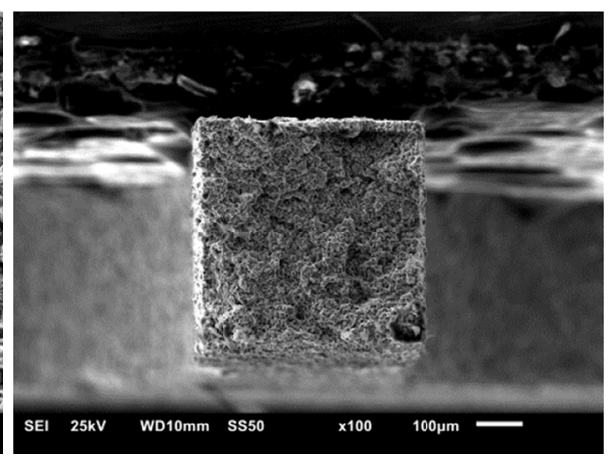

Fig. 9. Selected specimen fracture showing the microstructure of composite with $2 \mathrm{vol} \% \mathrm{TiB}_{2}$ sintered by SPS $\left(1100^{\circ} \mathrm{C}-30 \mathrm{~min}\right)$ after the tensile test carried out at: a) $400^{\circ} \mathrm{C}$ b) and c) $800^{\circ} \mathrm{C}$

a)

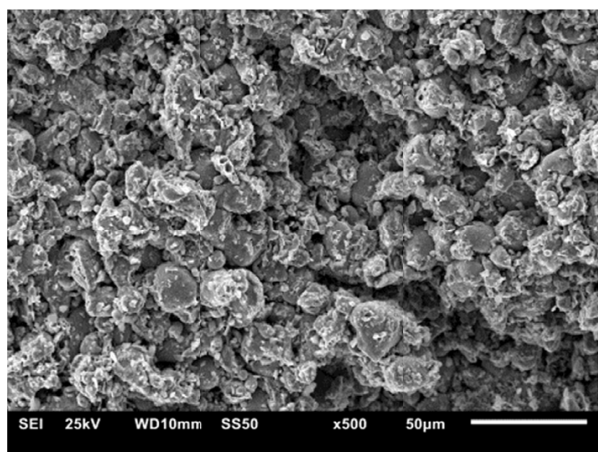

b)

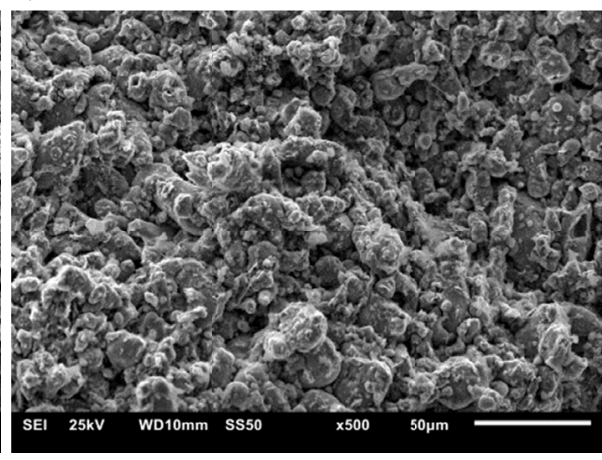

c)

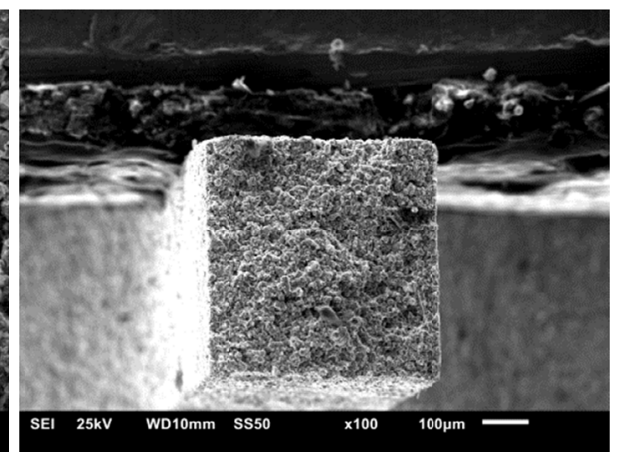

Fig. 10. Selected specimen fracture showing the microstructure of composite with 8 vol\% $\mathrm{TiB}_{2}$ sintered by SPS $\left(1100^{\circ} \mathrm{C}-30 \mathrm{~min}\right)$ after the tensile test carried out at: a) $400^{\circ} \mathrm{C} \mathrm{b}$ ) and c) $800^{\circ} \mathrm{C}$ 


\section{Acknowledgements}

The study was performed under Research Project N N507 222840 and statutory funds of Faculty of Mathematics, Physics and Technical Science, Pedagogical University in Krakow.

\section{REFERENCES}

[1] M. Tokita, Trends in Advanced SPS Spark Plasma Sintering Systems and Technology, Journal of the Society of Powder Technology Japan 30, 11, 790-804 (1993).

[2] X. Song, X. Liu, J. Zhang, Mechanism of conductive powder microstructure evolution in the process of SPS, Science in China Ser. E Engineering \& Materials Science 48, 3, 258-269 (2005).

[3] D.M. Hulber, A. Anders, J. Andersson, E.J. Lavernia, A.K. Mukherjee, A discussion on the absence of plasma in spark plasma sintering, Scripta Materialia 60, 10, 835-838 (2009).

[4] L. Jaworska, Receiving and application of diamond in machining, WNT, Warsaw (2007)

[5] F.P. Bundy, Ultra-high pressure apparatus, Physic Reports 3, 156175 (1988)

[6] I. Sulima, Consolidation of AISI316L Austenitic Steel - $\mathrm{TiB}_{2}$ Composites by SPS and HP-HT Technology, Sintering Techniques of Materials, Edited by Arunachalam Lakshmanan, Rijeka, InTech- Open Access Publisher, Chapter 7, 125-153 (2015).

[7] N. Saheb, Z. Iqbal, A. Khalil, A.S. Hakeem, N.A. Aqeeli, T. Laoui, A. Al-Qutub, R. Kirchner, Spark Plasma Sintering of Metals and Metal Matrix Nanocomposites: A Review, Journal of Nanomaterials, Hindawi Publishing Corporation, Article ID 983470, 13 pages, (2012) doi: 10.1155/2012/983470.

[8] H.U. Kessel, J. Hennicke, R. Kirchner, T. Kessel, Rapid sintering of novel materials by FAST/SPS-further development to the point of an industrial production process with high cost efficiency, FCT Systeme GmbH, Rauenstein, Germany (2010).

[9] D.H. Kwon, T.D. Nguyen, D. Dudina, Thermal stability and properties of $\mathrm{Cu}-\mathrm{TiB}_{2}$ nanocomposites prepared by combustion synthesis and spark-plasma sintering, Materials Science Forum 534-536, 2, 1517-1520 (2007).

[10] D.H. Kwon, D.N. Thuy, X.H. Khoa, J-W. Kum, P-P. Choi, J-S Kim, Y-S. Kwo, Mechanical, electrical and wear properties of Cu-TiB2 nanocomposites fabricated by MA-SHS and SPS, Journal of Ceramic Processing Research 7, 3, 275-279 (2006).

[11] S. Yamanaka, R. Gonda, A. Kawasaki, H. Sakamoto, Y. Mekuchi, M. Kuno, T. Tsukada, Fabrication and thermal properties of carbon nanotube/nickel composite by spark plasma sintering method, Materials Transactions 48, 9, 2506-2512 (2007).

[12] S. Kim, T. Sekino, T. Nakayama, M. Wada, J.S. Lee, K. Niihara, Pulse electric current sintering of alumina/nickel nanocomposites, Materials Research Innovations 7, 2, 57-61 (2003).

[13] J. Bhatt, N. Balachander, S. Shekher, R. Karthikeyan, D.R. Peshwe, B.S. Murty, Synthesis of nanostructured Al-Mg-SiO ${ }_{2}$ metal matrix composites using high-energy ball milling and spark plasma sintering, Journal of Alloys and Compounds 536, S35-S40 (2012).
[14] S. Bathula, R.C. Anandani, A. Dha, A.K. Srivastava, Synthesis and characterization of Al-alloy/SiCp nanocomposites employing high energy ball milling and spark plasma sintering, Advanced Materials Research 410, 224-227 (2012).

[15] N.AL Aqeeli, K. Abdullahi, A.S. Hakeem, C. Suryanarayana, T. Laoui, N. Saheb, Synthesis characterization and mechanical properties of SiC-reinforced A-based nanocomposites processed by MA and SPS, Powder Metallurgy 56, 149-157 (2013).

[16] I. Sulima, P. Putyra, P. Hyjek, T. Tokarski, Effect of SPS parameters on densification and properties of steel matrix composites, Advanced Powder Technology 26, 4, 1152-1161 (2015).

[17] A. Singh, S.P. Harimkar, Spark plasma sintering of in situ and ex situ iron-based amorphous matrix composites, Journal of Alloys and Compounds 497, 1-2, 121-126 (2010).

[18] K.R. Ravi, A. Murugesan, V. Udhayabanu, R. Subramanian, B.S. Murty, Microstructure and mechanical property of $\mathrm{Fe}-\mathrm{Al}_{2} \mathrm{O}_{3}$ nanocomposites synthesized by reactive milling followed by spark plasma sintering, Materials Science Forum 710, 291-296 (2012).

[19] X. Liu, E. Pagounis, J. Hellman, V.K. Lindroos, The Influence of reinforcement particle size distribution on the mechanical behavior of a stainless steel/tin composite, Metallurgical and Materials Transactions A 31, 309-318 (2000).

[20] I. Sulima, G. Boczkal, Micromechanical, high-temperature testing of steel- $\mathrm{TiB}_{2}$ composite sintered by High Pressure-High Temperature method, Materials Science and Engineering A 644, 76-78 (2015).

[21] B. Maruyama, W.H. Hunt, Discontinuously reinforced aluminum: current status and future direction. JOM 51, 11, 59-61 (1999).

[22] D.Z. Zhu, G.H. Wu, G.Q. Chen, Q. Zhang, Dynamic deformation behavior of a high reinforcement content $\mathrm{TiB}_{2} / \mathrm{Al}$ composite at high strain rates, Materials Science and Engineering A 487, 536540 (2008).

[23] O. Balci, D. Agaogullari, H. Gokce, I. Duman, M.L. Ovecoglu, Influence of $\mathrm{TiB}_{2}$ particle size on the microstructure and properties of $\mathrm{Al}$ matrix composites prepared via mechanical alloying and pressureless Sintering, Journal of Alloys and Compounds 586, S78-S84 (2014).

[24] G.B. Veeresh Kumar, C.S.P. Rao, N. Selvaraj, Mechanical and Tribological Behavior of Particulate Reinforced Aluminum Metal Matrix Composites - a review, Journal of Minerals \& Materials Characterization \& Engineering 10, 1, 59-91 (2011).

[25] J. Karwan-Baczewska, The properties of Fe-Ni-Mo-Cu-B materials produced via liquid phase sintering, Archives of Metallurgy and Materials 56, 3, 7890-796 (2011).

[26] G. Boczkal, Electrons charge concentration and melting point of bcc metals, Materials Letters 134, 162-164 (2014).

[27] I. Sulima, L. Jaworska, P. Figiel, Influence of processing parameters and different content of $\mathrm{TiB}_{2}$ ceramics on the properties of composites sintered by high temperature-high pressure (HT-HP) method, Archives of Metallurgy and Materials 59, 1, 205-209 (2014).

[28] I. Sulima, P. Figiel, P. Kurtyka, Austenitic stainless steel-TiB ${ }_{2}$ composites obtained by HP-HT method, Composites 4, 245-250 (2012). 